DOI: https://doi.org/10.24867/02AM06Lazic

\title{
UPOREDNA ANALIZA SISTEMA GRIJANJA TOPLOTNIM PUMPAMA I HIBRIDNIM SISTEMIMA
}

\section{HEAT PUMP AND HYBRID HEATING SYSTEMS COMPARATIVE ANALYSIS}

\author{
Dragan Lazić, Fakultet tehničkih nauka, Novi Sad
}

\begin{abstract}
Oblast - MAŠINSTVO
Kratak sadržaj - U ovom radu izvršena je uporedna analiza mogućih rješenja različitih sistema grijanja toplotnim pumpama $i$ hibridnim sistemima. Dato je objašnjenje procedure dimenzionisanja i izbora različitih dijelova sistema grijanja pomoću toplotnih pumpi sa različitim izvorima toplote. Izvršena je i tehnoekonomska analiza različitih sistema grijanja toplotnim pumpama. Na kraju rada date su i neke prednosti i mane poređenih sistema grijanja.
\end{abstract}

Ključne riječi: Grijanje, toplotne pumpe, izbor sistema

\begin{abstract}
In this paper, a comparative analysis of possible solutions for different heating systems with heat pumps and hybrid systems has been performed. Procedure of dimensioning and selection of different parts of the heating systems are also given. Technoeconomic analysis of various heating systems by heat pumps with different heat sources was made. In conclusion, advantages and disadvantages of different heating systems were explained.
\end{abstract}

Keywords: Heating, heat pumps, System selection

\section{UVOD}

Kako bi se došlo do podatka o isplativosti nekog projekta, odnosno u ovom slučaju, sistema grijanja pomoću toplotne pumpe, potrebno je uporediti više različitih podataka, izvršiti odabir sistema, odrediti njegovu namjenu, izvršiti dimenzionisanje, izbor opreme $\mathrm{i}$ na kraju uporediti odabrani sistem sa nekim drugim konvencionalnim sistemom za grijanje. $U$ ovom radu izvršena je analiza različitih sistema za grijanje i hibridnih sistema pomoću programskog paketa GeoTSOL [3]. U prvom dijelu rada, objašnjena je analiza različitih sistema grijanja u programskom paketu GeoTSOL.

Drugi dio rada se odnosi na tehnoekonomsku analizu različitih sistema grijanja sa toplotnim pumpama. Izvršeno je poređenje sistema sa vazdušnom toplotnom pumpom, toplotnom pumpom sa geotermalnim kolektorima, geotermalnim sondama, a na kraju je izvršena analiza hibridnog sistema za grijanje.

\section{NAPOMENA:}

Ovaj rad proistekao je iz master rada čiji mentor je bio doc. dr Aleksandar Anđelković.
Svi analizirani sistemi imaju dvojaku ulogu, odnosno, služe za grijanje i pripremu tople sanitarne vode. Nakon završene analize, izvršeno je poređenje bitnijih podataka dobijenih analizom. Na osnovu tih podataka, može se zaključiti da li postoji ekonomska opravdanost ugradnje sistema sa toplotnom pumpom.

\section{PREGLED, PODJELA I ZNAČAJ PRIMJENE TOPLOTNIH PUMPI I HIBRIDNIH SISTEMA}

Toplotna pumpa je uređaj koji pomoću uloženog rada, oduzima toplotu od okoline, koja se onda može na višem temperaturskom nivou koristiti za grijanje.

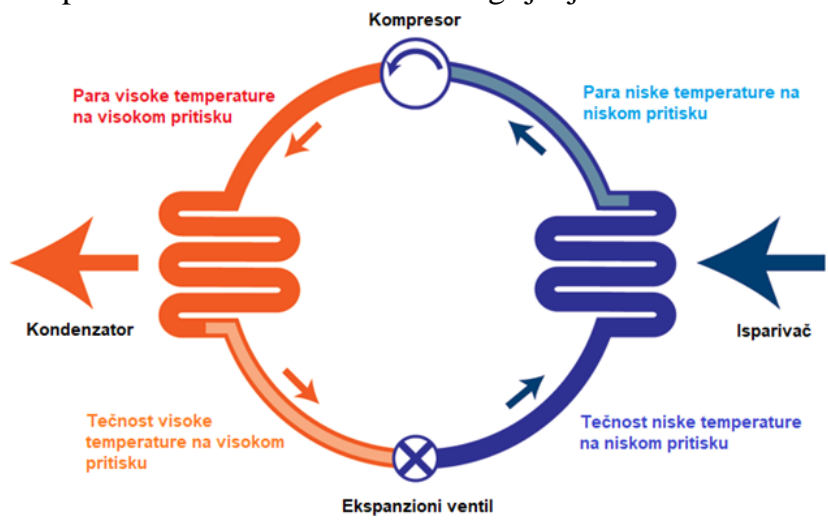

Slika 1. Osnovni ciklus toplotne pumpe

$\mathrm{Na}$ slici 1. prikazan je osnovni ciklus toplotne pumpe. Medijum koji se koristi za iskorišćenje toplote nekog niskotemperaturskog izvora toplote $\mathrm{u}$ toplotnoj pumpi naziva se rashladni medijum, a karakteriše ga niska temperatura ključanja. Ovaj medijum može da isparava na niskim temperaturama, pa $\mathrm{u}$ isparivaču on isparava preuzimajući toplotu iz okoline na niskom pritisku. Posle kompresora, ova para, sada visokog pritiska i visoke temperature, kondenzuje se u kondenzatoru predavajući toplotu okolini. Takva tečnost, nakon kondenzacije, prolazi kroz ekspanzioni ventil, čime se obara pritisak medijuma, nakon čega se dobija tečnost niskog pritiska $\mathrm{i}$ niske temperature. Takva tečnost ponovo prolazi kroz isparivač, čime se ciklus ponavlja. Osnovni izvori toplote [4] za toplotnu pumpu su: voda, vazduh, zemlja i okolina. Kako se toplotna pumpa može koristiti ne samo za grijanje, nego i za grijanje i pripremu tople sanitarne vode, sve su češći takvi sistemi. Kako bi se poboljšao rad sistema toplotne pumpe, moguće je kao podršku dijela sistema za pripremu tople sanitarne vode koristiti solarni kolektor. Ovakvi sistemi se nazivaju hibridnim sistemima. 


\section{PROJEKTOVANJE SISTEMA GRIJANJA TOPLOTNIM PUMPAMA POMOĆU PROGRAMSKOG PAKETA GEOTSOL}

Prilikom projektovanja sistema grijanja pomoću GeoTSOL-a prvi korak podrazumijeva odabir lokacije. Pomoću potprograma MeteoSyn [1] bira se lokacija i povlače se klimatski podaci za tu lokaciju. Izvor klimatskih podataka je servis „Meteonorm“ [2]. Treba imati u vidu da su dostupni podaci samo do 2005.god. Izvori toplote za toplotnu pumpu mogu biti [1] geotermalni kolektori, geotermalne sonde, spoljašnji vazduh, podzemne vode. Sistem može biti projektovan za grijanje, grijanje i pripremu tople sanitarne vode, a mogu se izabrati i hibridni sistemi. Prilikom izbora sistema, potrebno je voditi računa o tipu grijanja, odnosno, da li je to niskotemperatursko ili visokotemperatursko. Visokotemperatursko podrazumijeva radijatorsko grijanje, dok niskotemperatursko podrazumijeva zidno ili podno grijanje. Što se tiče sistema za pripremu tople sanitarne vode, on podrazumijeva definisanje podataka o potrošnji tople sanitarne vode po broju osoba. Može se izabrati sistem sa cirkulacijom tople sanitarne vode i bez. Treba imati u vidu da sistem sa cirkulacijom poskupljuje sistem, povećava gubitke, ali izbjegava se veće vrijeme odziva sistema, pa je topla sanitarna voda dostupna odmah.

Programski paket GeoTSOL omogućava izbor toplotne pumpe iz baze programa, ali je moguće unijeti i podatke o nekoj drugoj toplotnoj pumpi. Vrlo je bitno da se obrati posebna pažnja na izbor režima rada toplotne pumpe, odnosno da li će toplotna pumpa samostalno obezbjeđivati svu potrebnu količinu toplote ili će raditi u kombinaciji sa nekim pomoćnim izvorom toplote. Mogući režimi rada toplotne pumpe su: monovalentni, paralelni monoenergetski, alternativni monoenergetski i djelimično paralelni monoenergetski. Monovalentni režim rada predstavlja takav režim gdje toplotna pumpa obezbjeđuje cjelokupnu količinu potrebne toplotne energije. Kod paralelnog monoenergetskog režima rada, toplotna pumpa obezbjeđuje toplotnu energiju do određene ambijentalne temperature, a ispod te temperature, uključuje se pomoćni sistem koji služi kao podrška. Alternativni monoenergetski sistem funkcioniše slično kao prethodni sistem, samo što se ispod određene temperature toplotna pumpa isključuje. Djelimično paralelni monoenergetski režim rada podrazumijeva samostalni rad toplotne pumpe do neke temperature kada se uključuje pomoćni sistem, kada sistemi rade paralelno, a nakon temperature isključenja toplotne pumpe, pomoćni sistem nastavlja da radi samostalno. Pomoćni sistem podrazumijeva konvencionalni sistem grijanja, na primjer električni kotao, gasni kotao, itd.

Kod toplotnih pumpi sa geotermalnim sondama, potrebno je obratiti pažnju na dimenzionisanje primarnog kruga, odnosno na izvor toplote. Potrebno je definisati snagu cirkulacione pumpe, protok, temperaturu zemljišta, specifičnu količinu dobijene toplote po metru, nakon čega se dobija potrebna dužina sonde. Potrebna dužina sonde se dobija na osnovu jednačine [1]:

$$
l_{\text {geo }}=\frac{P_{T P, h l}}{\dot{q}_{L}}[m]
$$

gdje su:

$P_{T P, h l}$ - rashladni kapacitet toplotne pumpe,

$\dot{q}_{L}$ - specifična toplota koja se preuzima iz zemljišta.

Kod sistema sa geotermalnim kolektorima, potrebno je voditi računa o potrebnoj površini kolektora, dubini polaganja kolektora, snazi cirkulacione pumpe, protoku. Osim toga, kao i kod sistema sa geosondama, posebnu pažnju treba posvetiti definisanju specifičnog toplotnog kapaciteta zemljišta i količini dobijene toplotne energije.

Sistem sa vazdušnom toplotnom pumpom ima odmah dostupan izvor toplote koji ne zahtjeva investicije sa strane primarnog kruga, međutim, mora se izbjeći smrzavanje sistema, pa toplotna pumpa mora imati i sistem odmrzavanja. Tamo gdje se koristi podzemna voda kao izvor toplote, mora se definisati temperaturski opseg toplotnog izvora u relevantnom periodu.

Sistem sa toplotnom pumpom je najčešće opremljen akumulacionim (,buffer“) rezervoarom, a ako se koristi i za pripremu tople sanitarne vode, opremljen je i rezervoarom tople sanitarne vode. Što se tiče solarnog sistema, njegovo definisanje podrazumijeva odabir solarnog kolektora određene snage, broj kolektora, ugao postavljanja, kao i potrebne dužine cjevovoda na osnovu čega se računaju i gubici.

Nakon definisanja i dimenzionisanja svih dijelova sistema, simulacijom se dobijaju podaci o efikasnosti sistema, potrošnji električne energije, dobijenoj količini toplotne energije, gubicima i tako dalje. Najvažniji indikator predstavlja sezonski faktor performansi (SPF„seasonal performance factor"), odnosno pokazatelj korisnosti toplotne pumpe, odnosno cjelokupnog sistema, koji se računa prema [1] jednostavnoj formuli:

$$
S P F=\frac{\text { benefiti }}{\text { troškovi }}
$$

U dijelu finansijske analize vrši se analiza ekonomske opravdanosti sistema. Finansijskom analizom se dobija modifikovana stopa povrata, odnosno MIRR, koji predstavlja jasan indikator isplativosti, odnosno što je MIRR veći, sistem je isplativiji. Osim MIRR, dobija se i cijena grijanja po kWh toplotne energije, koja je značajna u pogledu poređenja sistema sa nekim drugim sistemima.

\section{TEHNOEKONOMSKA ANALIZA RAZLIČITIH SISTEMA SA TOPLOTNOM PUMPOM}

Izvršena je analiza četiri različita sistema sa toplotnim pumpama, odnosno sistem sa vazdušnom toplotnom pumpom, toplotnom pumpom sa geotermalnim sondama, geotermalnim kolektorima, kao i hibridnog sistema koji predstavlja kombinaciju toplotne pumpe sa geosondama i solarnih kolektora. Sistemi su opremljeni toplotnom pumpom, akumulacionim i rezervoarom tople sanitarne vode, kao i razvodima za grijanje i pripremu tople sanitarne vode. Kod hibridnog sistema, izabran je kombinovani rezervoar, tako da je izbjegnuta upotreba dvije posude. 
U tabelama u nastavku su dati rezultati proračuna za različite sisteme sa toplotnim pumpama. Dati su sezonski faktori performansi, količine dobijene toplotne energije, kao i potrošnje električne energije.

Tabela 1. Rezultati proračuna sistema sa vazdušnom TP

\begin{tabular}{|c|c|c|}
\hline \multicolumn{2}{|c|}{ Rezultati proračuna } & Vrijednost \\
\hline \multicolumn{2}{|c|}{ SPF toplotne pumpe } & 3,7 \\
\hline \multicolumn{2}{|c|}{ SPF sistema toplotne pumpe } & 3,7 \\
\hline \multicolumn{2}{|c|}{ Godišnja potrošnja električne energije } & $4430 \mathrm{kWh}_{\text {god }}$ \\
\hline \multicolumn{2}{|c|}{ Godišnje dobijena toplotna energija } & $16520 \mathrm{kWh}_{\mathrm{god}}$ \\
\hline \multirow{2}{*}{$\begin{array}{l}\text { Iskorišćena } \\
\text { energija }\end{array}$} & Za grijanje & $13596 \mathrm{kWh}_{\mathrm{god}}$ \\
\hline & Za TSV & $2232 \mathrm{kWh}_{\mathrm{god}}$ \\
\hline \multicolumn{2}{|c|}{ Gubici rezervoara } & $681 \mathrm{kWh}_{\mathrm{god}}$ \\
\hline
\end{tabular}

Tabela 2. Rezultati proračuna sistema TP sa geokolektorima

\begin{tabular}{|c|c|c|}
\hline \multicolumn{2}{|c|}{ Rezultati proračuna } & Vrijednost \\
\hline \multicolumn{2}{|c|}{ SPF toplotne pumpe } & 3,4 \\
\hline \multicolumn{2}{|c|}{ SPF sistema toplotne pumpe } & 3,4 \\
\hline \multicolumn{2}{|c|}{ Godišnja potrošnja električne energije } & $4870 \mathrm{kWh}_{\mathrm{god}}$ \\
\hline \multicolumn{2}{|c|}{ Godišnje dobijena toplotna energija } & $16541 \mathrm{kWh}_{\text {god }}$ \\
\hline \multirow{2}{*}{$\begin{array}{c}\text { Iskorišćena } \\
\text { energija }\end{array}$} & Za grijanje & $13596 \mathrm{kWh}_{\text {god }}$ \\
\hline & Za TSV & $2233 \mathrm{kWh}_{\text {god }}$ \\
\hline \multicolumn{2}{|c|}{ Gubici rezervoara } & $686 \mathrm{kWh}_{\mathrm{god}}$ \\
\hline
\end{tabular}

Tabela 3. Rezultati proračuna sistema TP sa geosondama

\begin{tabular}{|c|c|c|}
\hline \multicolumn{2}{|c|}{ Rezultati proračuna } & Vrijednost \\
\hline \multicolumn{2}{|c|}{ SPF toplotne pumpe } & 3,4 \\
\hline \multicolumn{2}{|c|}{ SPF sistema toplotne pumpe } & 3,4 \\
\hline \multicolumn{2}{|c|}{ Godišnja potrošnja električne energije } & $4819 \mathrm{kWh}_{\mathrm{god}}$ \\
\hline \multicolumn{2}{|c|}{ Potrošnja el. energije za pomoćne sisteme } & $99 \mathrm{kWh}_{\text {god }}$ \\
\hline \multicolumn{2}{|c|}{ Godišnje dobijena toplotna energija } & $16545 \mathrm{kWh}_{\mathrm{god}}$ \\
\hline \multirow{2}{*}{$\begin{array}{c}\text { Iskorišćena } \\
\text { energija }\end{array}$} & Za grijanje & $13596 \mathrm{kWh}_{\mathrm{god}}$ \\
\hline & Za TSV & $2233 \mathrm{kWh}_{\mathrm{god}}$ \\
\hline \multicolumn{2}{|c|}{ Gubici rezervoara } & $690 \mathrm{kWh}_{\mathrm{god}}$ \\
\hline
\end{tabular}

Tabela 4. Rezultati proračuna hibridnog sistema

\begin{tabular}{|l|c|}
\hline \multicolumn{1}{|c|}{ Rezultati proračuna } & Vrijednost \\
\hline SPF toplotne pumpe & 3,4 \\
\hline SPF sistema toplotne pumpe & 3,4 \\
\hline SPF cjelokupnog sistema (TP + solar) & 3,9 \\
\hline Godišnja potrošnja električne energije & $4220 \mathrm{kWh}_{\text {god }}$ \\
\hline Godišnje dobijena toplotna energija & $16452 \mathrm{kWh}_{\text {god }}$ \\
\hline Iskorišćena energija & $15813 \mathrm{kWh}_{\text {god }}$ \\
\hline Gubici Solarni sistem & $1872 \mathrm{kWh}_{\text {god }}$ \\
\hline \multicolumn{2}{|c|}{} \\
\hline Udio solarnog sistema & $15,9 \%$ \\
\hline Udio solarnog sistema u pripremi TSV & $53,7 \%$ \\
\hline Efikasnost solarnog sistema & $36 \%$ \\
\hline $\begin{array}{l}\text { Dozračena toplota na aktivnu površinu } \\
\text { kolekt. }\end{array}$ & $7240 \mathrm{kWh}_{\text {god }}$ \\
\hline Dobijena topl. energija od solarnih kolektora & $3411 \mathrm{kWh}_{\text {god }}$ \\
\hline
\end{tabular}

U sledećoj tabeli dat je prikaz bitnijih podataka analize različitih sistema sa toplotnim pumpama. Može se primijetiti da je najjeftiniji sistem sa vazdušnom TP, dok je hibridni sistem najskuplji, zbog čega je i cijena grijanja najmanja kod sistema sa vazdušnom TP, a najveća kod hibridnog sistema.

Najveći SPF ima hibridni sistem od 3,9. Najveći MIRR se dobija kod sistema sa vazdušnom TP od čak $15,75 \%$, ali treba uzeti u obzir da je hibridni sistem više od tri puta skuplji, ali se i dalje ostvaruje pozitivan MIRR.

Tabela 5. Poređenje podataka razlicitih sistema sa TP

\begin{tabular}{|l|c|c|c|c|}
\hline Sistem sa TP & $\begin{array}{c}\text { Cijena } \\
\text { sistema [€] }\end{array}$ & $\begin{array}{c}\text { Cijena } \\
\text { grijanja } \\
{[€ / \mathbf{k W h}]}\end{array}$ & SPF & $\begin{array}{c}\text { MIRR } \\
{[\%]}\end{array}$ \\
\hline Vazdušna TP & 4750 & 0,045 & 3,7 & 15,75 \\
\hline $\begin{array}{l}\text { TP sa } \\
\text { geotermalnim } \\
\text { kolektorima }\end{array}$ & 11050 & 0,065 & 3,4 & 4,05 \\
\hline $\begin{array}{l}\text { TP sa } \\
\text { geotermalnim } \\
\text { sondama }\end{array}$ & 14350 & 0,075 & 3,4 & 1,83 \\
\hline $\begin{array}{l}\text { Hibridni } \\
\text { sistem }\end{array}$ & 18512 & 0,086 & $3,4 / 3,9^{*}$ & 0,23 \\
\hline
\end{tabular}

* Napomena: zbog toga što se radi o hibridnom sistemu, date su vrijednosti SPF toplotne pumpe, kao i cjelokupnog sistema, respektivno.

\section{ZAKLJUČAK}

Kao što se može vidjeti iz svega prethodnog, u ovom radu dato je objašnjenje projektovanja sistema sa toplotnim pumpama u programskom paketu GeoTSOL.

Dato je objašnjenje načina izbora dijelova sistema kao i njihovog dimenzionisanja.

Drugi dio rada predstavlja tehnoekonomska analiza različitih sistema za grijanje i pripremu tople sanitarne vode pomoću toplotnih pumpi i hibridnih sistema. Poređenjem podataka dobijenih analizom različitih sistema, može se donijeti nekoliko zaključaka.

Sa strane efikasnosti sistema, najveću efikasnost, odnosno SPF ima hibridni sistem od 3,9 zbog toga što je količina električne energije utrošena za proizvodnju toplotne energije manja za količinu toplotne energije koja je dobijena putem solarnog kolektora, pa je sa strane odnosa utrošene električne i dobijene toplotne energije ovakav sistem najpovoljniji.

Nešto manji SPF ima sistem sa vazdušnom toplotnom pumpom, od 3,7. Najmanji SPF imaju sistemi sa geosondama i geokolektorima, od 3,4. Cijena grijanja predstavlja odnos godišnjih troškova sistema i dobijene toplotne energije iz sistema, pa pruža dobru informaciju o isplativosti ugradnje nekog od sistema.

Najmanju cijenu grijanja ima sistem sa vazdušnom toplotnom pumpom od $0,045 € / \mathrm{kWh}$, zatim slijede sistem sa geokolektorima i geosondama sa cijenama grijanja od $0,065 € / \mathrm{kWh}$ i $0,075 € / \mathrm{kWh}$, respektivno. Najveću cijenu grijanja ima hibridni sistem od čak $0,086 € / \mathrm{kWh}$.

Visoke cijene grijanja kod hibridnog, sistema sa geosondama i sistema sa geokolektorima, rezultat su visoke cijene opreme, koja proističe iz specifičnosti načina iskorišćenja izvora toplote.

Dobar indikator isplativosti sistema predstavlja i MIRR, odnosno stopa povrata projekta, što je on veći, veća je i isplativost sistema. 
Najveći MIRR ima sistem sa vazdušnom toplotnom pumpom, od $15,75 \%$, a slijede sistemi sa geotermalnim kolektorima, geosondama sa MIRR od 4,05\% i $1,83 \%$ respektivno, dok najmanji MIRR ima hibridni sistem od $0,23 \%$, zbog visoke početne investicije.

Kako se vidi u prethodnom dijelu, najveću isplativost ima sistem sa vazdušnom toplotnom pumpom u pogledu korišćene tehnologije i cijene, zbog čega ovakav sistem $u$ odnosu na ostale sisteme razmatrane u ovom radu ima očitu prednost.

\section{LITERATURA}

[1] GeoT*SOL basic, Version 2.0, Planning and designing heat pump systems

[2] http://www.meteonorm.com/, (pristupljeno 22.10.2017. 19:09h)

[3] http://www.valentinsoftware.com/en/products/heat-pumps/33/geotsol, (pristupljeno 22.10.2017. 14:00)

[4] H. Reknagel, E. Šprenger, Grejanje i klimatizacija, Interklima, Vrnjačka Banja, 2004.

[5] http://www.mre.gov.rs/latinica/faq-energetskaefikasnost-obnovljiviizvori.php\#_Mere_podsticaja_za_1, (pristupljeno 3.10.2018. 07:00)

\section{Kratka biografija:}

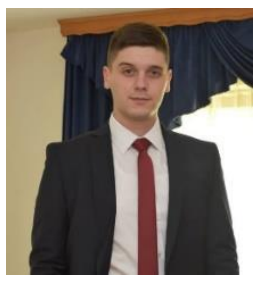

Dragan Lazić rođen je u Bogenu, SR Njemačka 1992. god. Master rad odbranio je 2018. godine na Fakultetu tehničkih nauka iz oblasti Mašinstva - Termotehnika.

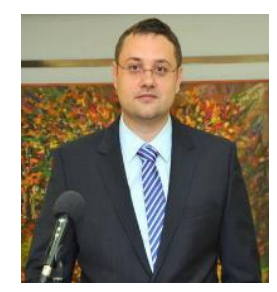

Aleksandar Anđelković rođen je u Šapcu 1981. god. Doktorirao je 2015. god., a od 2015. je u zvanju docent. Oblast interesovanja su Nekonvencionalni sistemi grijanja i hlađenja. 